Research Article

\title{
Effect of educational intervention on the knowledge and attitude on prescribing amongst interns of a tertiary care hospital: a questionnaire based study
}

\author{
Revathy Saravanan*, Sakthibalan M., Bikash Ranjan Meher, Balabalajee J.
}

Department of Pharmacology, Sri Venkateshwaraa Medical College Hospital and Research Centre, Puducherry, India

Received: 23 December 2015 Accepted: 03 February 2016

*Correspondence to:

Dr. Revathy Saravanan,

Email: dr_rsmail@yahoo.co.in

Copyright: () the author(s), publisher and licensee Medip Academy. This is an openaccess article distributed under the terms of the Creative Commons Attribution NonCommercial License, which permits unrestricted noncommercial use, distribution, and reproduction in any medium, provided the original work is properly cited.

\begin{abstract}
Background: Prescribing correct therapy is the essential part of physicians and therefore, adequate knowledge and confidence on drugs efficacy, safety, cost, and convenience is important. Understanding the knowledge and perceptions of medical students will help to identify the problems in clinical pharmacology teaching. Prescribing performance and competence can be significantly improved by training and giving feedback to the prescriber. The objective of the study was to evaluate and compare the effect of educational intervention in enhancing the knowledge of medical interns on prescribing practice.

Methods: A Cross sectional, Educational Interventional observational study was conducted using two copies of a pretested validated questionnaire (Pre \& Post CME) with 15 questions among 110 MBBS interns. They were subjected to a continuous medical education on rational prescription writing followed by a hand's on training on prescription writing in which they were divided into 9 batches and asked to prescribe for the case scenario given to them and the same was audited and feedback was given.

Results: Out of 110 internees', 105 (95.50\%) and 95 (96.90\%) had completely filled the pre \& post educational intervention questionnaire. The overall knowledge and attitude of interns has improved after the intervention. Significant increase $(\mathrm{P}$ value $<0.0001)$ in the Mean + Standard deviation value from $5.81+2.1$ to $7.35+3.18$ is noted on applying Paired $t$ Test. All the prescriptions were rational. The formats of their prescriptions were scrutinized and the precise way of writing the same was explained to the interns.

Conclusions: This study clearly shows that early sensitization of Physicians about rational prescription writing during Internship phase by means of educational intervention/training program can reduce the number of prescription errors.
\end{abstract}

Keywords: MBBS interns, Prescribing practice, Educational intervention

\section{INTRODUCTION}

Pharmacology is the backbone of Clinical Medicine. ${ }^{1}$ Prescribing correct therapy is the essential part of physicians and therefore, adequate knowledge and confidence on drugs efficacy, safety, cost, and convenience is important. ${ }^{2}$ Lessons in Pharmacology enrich medical students' knowledge and skill about different drugs and their utility in various diseases. ${ }^{3}$

Aim of pharmacology should be to produce rational prescribers. Irrational prescribing leads to huge loss of lives and money. Inadequate knowledge leads to irrational prescribing. A report from National Academy of Science Institute of Medicine estimated that as many as 98,000 people die every year because of the mistakes committed by medical professionals in hospitals. Prescription errors account for $70 \%$ of medication errors that could potentially result in adverse effects. ${ }^{4}$ Few studies have shown prescribing error rate at $34 \%$ of total prescription. ${ }^{5}$

Every medical graduate/Physician must have an intention to prescribe rationally. It is Pharmacology, which teaches 
rationality of prescribing in undergraduate medical course. Thus, Pharmacology is an essential part of the medical curriculum. Although the interns work is usually under the supervision of a senior consultant, there will be occasions, when they have to make their own decision. As the drug market in India, is rapidly booming. Interns' are sometime confused to pick out a drug from the therapeutic choices available.

Initiatives taken by the government to promote rational prescribing will not succeed unless proper steps are taken for rational prescribing in clinical pharmacology teaching itself. Understanding the knowledge and perceptions of medical students will help to identify the problems in clinical pharmacology teaching which can be modified if needed. A systematic review of 47 studies done by Gritta Kamrudeen, et al has suggested that prescribing performance and competence can be significantly improved by training with WHO Guide to good prescribing as guide and by giving feedback to the prescriber which can be also be enhanced by continuing medical education giving academic details. ${ }^{6}$ Errors in prescription by not adhering to the WHO guidelines regarding core indicators have been expressed in many prescription audit studies among practicing physicians and also by interns during their Primary Health centres postings. With this background the present cross sectional study was organized.

\section{Aim \& objective}

To evaluate and compare the effect of educational intervention in enhancing the knowledge of medical interns on prescribing practice with the following objectives.

1. To understand the current status of the knowledge of clinical pharmacology among Interns.

2. To assess the knowledge and attitude of Interns on Prescribing before and after educational intervention.

\section{METHODS}

A Cross sectional, Educational Interventionalobservational study was carried out at a tertiary care teaching hospital in Pondicherry among the 100 medical interns.

\section{Inclusion criteria}

1. Sex: Both male and Female

2. Minimum educational Qualification: Medical Intern

3. Interns giving written informed consent.

\section{Exclusion criteria}

1. Medical Interns not willing to participate.
A pre tested structured questionnaire designed to assess knowledge and attitude was used.

Two copies of a pretested validated questionnaire (Pre evaluation and post evaluation questionnaire) consisting of 15 questions were distributed among individual interns. The questionnaire was in Standard English. For better quality of data, investigator explained the questionnaire to the participants. The pre evaluation questionnaire was filled and submitted by the Interns before the start of the educational intervention. This was followed by an educational intervention on rational prescription and clinical pharmacology in the form of Continuous Medical Education. At the end of the session, the post evaluation questionnaire was also filled and submitted by individual interns. The participants were then divided in to nine different groups and a clinical scenario was given to each group to write the prescription as hands on experience. The qualitative and quantitative analysis was done on submitted prescriptions and feedback was also given so that their prescribing knowledge can be improved for future application.

\section{Statistical analysis}

- Only completely filled questionnaires were taken up for analysis. The data were categorized and coded.

- The pre evaluation and post evaluation questionnaires were analysed by scoring (1point for yes \& 0 for No-maximum of 13 - which includes a separate score of 6 for question number 2) and compared using paired $\mathrm{t}$ test and chi square (wherever applicable) for statistical significance of $\mathrm{p}$ value $<0.05$.

- The data for questions $5,7,8,9,14$ \& 15- was expressed as percentages.

\section{RESULTS}

We have analysed 110 Questionnaires of Interns. Out of which 105 (response percentage was 95.5\%) were completely filled up Questionnaire before the conduct of the educational intervention and 98 Questionnaire after the educational intervention out of which 95 (response percentage was $96.9 \%$ ) were completely filled up questionnaires on prescribing amongst interns. Table 1 gives a summary of the questions that were put forth to the interns and their response percentage before and after the educational intervention.

A total scoring of 13 was given for both the pre and post educational intervention session. Mean value \pm standard deviation are $5.81 \pm 2.1$ (Pre) and $7.35 \pm 3.18$ (Post) Paired $t$ Test was applied for the same and it was found out that the $\mathrm{p}$ value is $<0.0001$ and there is a significant improvement in the total score after the educational intervention on rational prescription among interns. Total scoring for obtained by the study participants before and after the educational intervention is shown in Table 2. 
Table 1: Questions that were put forth to the Interns and their response percentage before and after the educational intervention.

\begin{tabular}{|c|c|c|c|c|}
\hline $\begin{array}{l}\text { S. } \\
\text { No. }\end{array}$ & Question & Response & $\begin{array}{l}\text { Pre } \\
\text { intervention } \\
\text { percentage } \\
(\mathbf{n}=\mathbf{1 0 5})\end{array}$ & $\begin{array}{l}\text { Post } \\
\text { intervention } \\
\text { percentage } \\
(\mathbf{n}=95)\end{array}$ \\
\hline 1 & $\begin{array}{l}\text { Do you know the different components in } \\
\text { the prescription format? }\end{array}$ & Yes & $65.09 \%$ & $92.63 \%$ \\
\hline 2 & $\begin{array}{l}\text { If yes Mention each component and the } \\
\text { information's needed to be recorded in each: }\end{array}$ & $\begin{array}{l}\text { a. Superscription: } \\
\text {-Doctor \& Patient details } \\
\text { b. Inscription } \\
\text {-Diagnosis \& Treatment given } \\
\text { c. Subscription } \\
\text {-Follow up, advice \& Doctors } \\
\text { signature }\end{array}$ & $\begin{array}{l}\text { 2a) } 28.30 \% \\
\text { 2b) } 31.01 \% \\
\text { 2c) } 27.36 \%\end{array}$ & $\begin{array}{l}\text { 2a) } 63.16 \% \\
\text { 2b) } 60.00 \% \\
\text { 2c) } 54.74 \%\end{array}$ \\
\hline 3 & Do you know what is generic name? & Yes & $89.62 \%$ & $96.84 \%$ \\
\hline 4 & Do you know what is trade name? & Yes & $98.11 \%$ & $95.79 \%$ \\
\hline 5 & $\begin{array}{l}\text { Do you write medicines in: generic name / } \\
\text { trade name? }\end{array}$ & $\begin{array}{l}\text { a. Generic name } \\
\text { b. Trade name }\end{array}$ & $\begin{array}{l}a=57.5 \% \\
b=35.9 \% \\
a, b=6.6 \%\end{array}$ & $\begin{array}{l}a=78.9 \% \\
b=18.9 \% \\
a, b=2.2 \%\end{array}$ \\
\hline 6 & $\begin{array}{l}\text { Do you know the advantages of using } \\
\text { generic name? }\end{array}$ & Yes & $82.08 \%$ & $95.79 \%$ \\
\hline 7 & How do you plan your treatment plan? & $\begin{array}{l}\text { a. Following prescribing } \\
\text { behaviour of seniors } \\
\text { b. Clinical teachers } \\
\text { c. Decide by yourself } \\
\text { d. Following standard guide } \\
\text { lines }\end{array}$ & $\begin{array}{l}a=14.5 \% \\
b=47 \% \\
c=3 \% \\
d=29.5 \% \\
b, d=3 \% \\
c, d=3 \%\end{array}$ & $\begin{array}{l}a=6.3 \% \\
b=35.8 \% \\
c=7.4 \% \\
d=40 \% \\
a, b=3.1 \\
b, d=5.3 \% \\
c, d=3.1 \\
a, b, c, d=1 \%\end{array}$ \\
\hline 8 & How do you decide the treatment? & $\begin{array}{l}\text { a. Based on disease only } \\
\text { b. For patient's satisfaction }\end{array}$ & $\begin{array}{l}a=80.9 \% \\
b=13.3 \% \\
a, b=5.8 \%\end{array}$ & $\begin{array}{l}a=83.2 \% \\
b=8.4 \% \\
a, b=8.4 \%\end{array}$ \\
\hline 9 & $\begin{array}{l}\text { What is your source of information about } \\
\text { medicines? }\end{array}$ & $\begin{array}{l}\text { a. Teachers b. Text books c. } \\
\text { Reference like CIMS, MIMS } \\
\text { d. Hospital formularies }\end{array}$ & $\begin{array}{l}a=24.8 \% \\
b=24.8 \% \\
c=23.8 \% \\
d=1.9 \% \\
a, b=10.5 \% \\
b, c=0.9 \% \\
a, c=3.8 \% \\
a, d=0.9 \% \\
a, b, c=6.8 \% \\
a, b, c, d=0.9 \%\end{array}$ & $\begin{array}{l}a=24.2 \% \\
b=21 \% \\
c=20 \% \\
d=3.2 \% \\
a, b=8.4 \% \\
b, c=3.2 \% \\
a, c=6.3 \% \\
a, d=2.1 \% \\
a, b, c=6.3 \% \\
a, b, c, d=5.3 \%\end{array}$ \\
\hline 10 & Do you know about $\mathrm{P}$ drug concept? & Yes & $32.08 \%$ & $83.16 \%$ \\
\hline 11 & $\begin{array}{l}\text { Are you aware of scheduled and controlled } \\
\text { drug regulations? }\end{array}$ & Yes & $39.62 \%$ & $78.95 \%$ \\
\hline 12 & $\begin{array}{l}\text { Prescribing writing exercises was useful and } \\
\text { understandable in } 2^{\text {nd }} \text { year M.B.B.S. }\end{array}$ & Yes & $83.02 \%$ & $91.58 \%$ \\
\hline 13 & $\begin{array}{l}\text { What do you think about your prescribing } \\
\text { writing? }\end{array}$ & $\begin{array}{l}\text { a. Rational b. Irrational } \\
\text { c. Do not know }\end{array}$ & $\begin{array}{l}a=61.9 \% \\
b=11.4 \% \\
c=26.7 \%\end{array}$ & $\begin{array}{l}a=77.9 \% \\
b=7.3 \% \\
c=14.8 \%\end{array}$ \\
\hline 14 & $\begin{array}{l}\text { How do you think your prescribing skill can } \\
\text { be improved? }\end{array}$ & $\begin{array}{l}\text { a. Training /refreshing before } \\
\text { starting internship } \\
\text { b: Any other suggestions }\end{array}$ & $\begin{array}{l}a=95.2 \% \\
b=4.8 \%\end{array}$ & $\begin{array}{l}a=95.8 \% \\
b=4.2 \%\end{array}$ \\
\hline 15 & $\begin{array}{l}\text { Do you think computerized transmission of } \\
\text { prescriptions with standard Prescription } \\
\text { format will help to avoid possible errors? }\end{array}$ & $\begin{array}{l}\text { a. Yes } \\
\text { b. No }\end{array}$ & $\begin{array}{l}a=47.6 \% \\
b=52.4 \%\end{array}$ & $\begin{array}{l}a=68.4 \% \\
b=31.6 \%\end{array}$ \\
\hline
\end{tabular}


Table 2: Total scoring for the questionnaire (Statistical analysis done by t-test).

\begin{tabular}{|c|c|c|c|c|}
\hline & Mean & $\begin{array}{l}\text { Standard } \\
\text { deviation }\end{array}$ & $\begin{array}{l}\text { Standard } \\
\text { error }\end{array}$ & $P$ value \\
\hline $\begin{array}{l}\text { Prior to } \\
\text { educational } \\
\text { intervention } \\
(n=105)\end{array}$ & 5.81 & 2.1 & 0.2 & \multirow{2}{*}{$<0.0001$} \\
\hline $\begin{array}{l}\text { Post } \\
\text { educational } \\
\text { intervention } \\
(n=95)\end{array}$ & 7.35 & 3.18 & 0.3 & \\
\hline
\end{tabular}

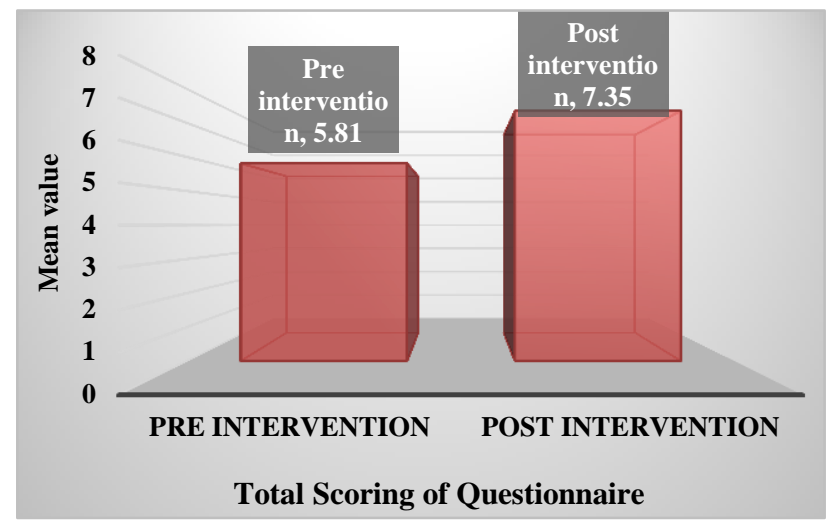

Figure 1: Total score analysis of the questionnaire.

And a separate score of 6 was given for Question number 2. Mean value \pm standard deviation are $0.88 \pm 0.12$ (Pre) and $1.61 \pm 0.16$ (Post). On applying paired $t$ Test for the same it was found out that the $p$ value is 0.0004 and there is a significant improvement in the scoring after giving the educational intervention. Thus there is a significant improvement in the knowledge about the prescription format among interns after the educational intervention. Effect of CME in enhancing the knowledge regarding the different components of a prescription namely superscription, inscription and subscription and the information's they should carry is depicted in Table 3 \& Figure 2.

Table 3: Scoring for the questionnaire on knowledge on the components of prescription format (Statistical analysis done by t-test).

\begin{tabular}{|lll|l|}
\hline & Mean & $\begin{array}{l}\text { Standard } \\
\text { error mean }\end{array}$ & P value \\
\hline $\begin{array}{l}\text { Prior to } \\
\text { educational }\end{array}$ & 0.88 & 0.12 \\
$\begin{array}{l}\text { intervention } \\
(\mathrm{n}=105)\end{array}$ & $<0.0004$ \\
\hline $\begin{array}{l}\text { Post } \\
\text { educational } \\
\text { intervention } \\
(\mathrm{n}=95)\end{array}$ & 1.61 & 0.16 \\
\hline
\end{tabular}

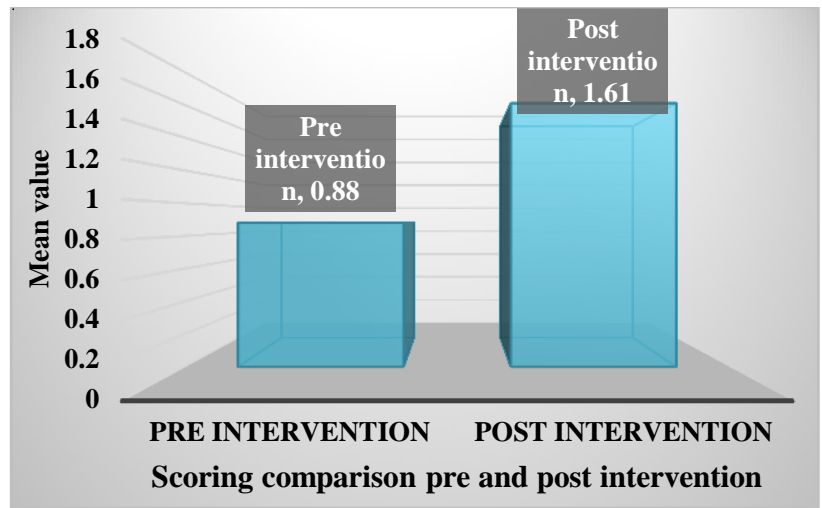

Figure 2: Scoring for the knowledge on components of prescription format.

Before the educational intervention there were $57.5 \%$ of Interns who preferred to prescribe drugs in Generic name and post educational intervention $78.9 \%$ of Interns $h$ opted to prescribe drugs in Generic name after recognizing the advantages of Generic name. There is a significant improvement in the knowledge about the generic drugs which was confirmed by applying Chi Square test. $\mathrm{P}$ value was $<0.0005$. (There is also a significant improvement in the knowledge about the $\mathrm{P}$ drug concept ( $\mathrm{P}$ value $<0.0005$ on applying chi square and fisher's exact test) and Scheduled \& controlled drug regulations ( $\mathrm{P}$ value $<0.0001$ on applying chi square and fisher's exact test) after the educational intervention (Table 4, Figure 3 \& Figure 4).

Table 4: Usage of generic and trade names while prescribing.

\begin{tabular}{|lcll|}
\hline \multicolumn{1}{|c|}{$\begin{array}{l}\text { Pre } \\
\text { intervention }\end{array}$} & $\begin{array}{l}\text { Post } \\
\text { intervention }\end{array}$ & P value \\
\hline $\begin{array}{l}\text { Generic name } \\
\text { use }\end{array}$ & $57.50 \%$ & $78.90 \%$ & $<0.0005$ \\
\hline $\begin{array}{l}\text { Trade name } \\
\text { use }\end{array}$ & $35.90 \%$ & $18.90 \%$ & \\
\hline Usage of both & $6.60 \%$ & $2.20 \%$ & \\
\hline $\begin{array}{l}\text { Knowledge of } \\
\text { P drug concept }\end{array}$ & $32.08 \%$ & $83.16 \%$ & $<0.0005$ \\
\hline $\begin{array}{l}\text { Knowledge of } \\
\text { scheduled \& } \\
\text { controlled } \\
\text { drug } \\
\text { regulations }\end{array}$ & $39.62 \%$ & $78.95 \%$ & $<0.0001$ \\
\hline
\end{tabular}

On further analysis of the Questionnaire, it was found out that $29 \%$ of interns preferred standard guidelines \& $47 \%$ preferred Clinical teachers while deciding the treatment plan and after the educational intervention $40 \%$ opted to follow standard guidelines and $35 \%$ follow clinical teachers while deciding the treatment plan. Significant increase ( $\mathrm{P}$ value $<0.001$ on applying Chi square test) in the percentage of interns from $47.6 \%$ to $68.4 \%$ after the educational intervention have opted for computerized 
transmission of prescriptions with standard prescription format to avoid possible errors (Table 5 \& Figure 5).

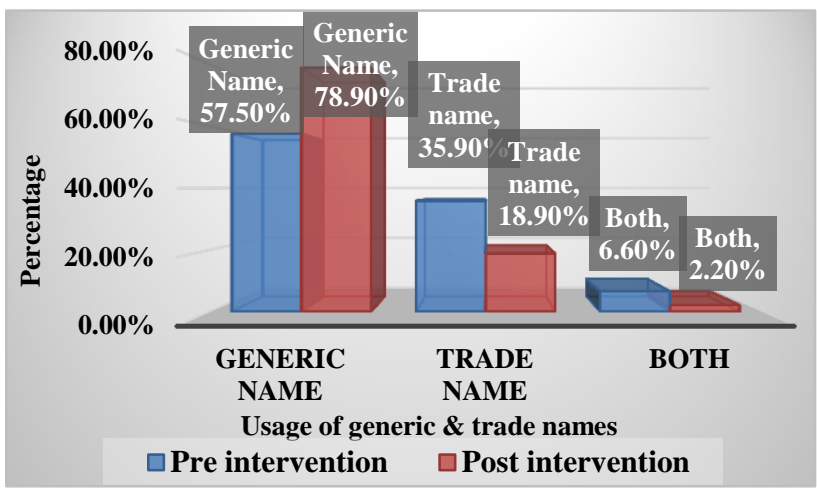

Figure 3: Usage of generic and trade names while prescribing.

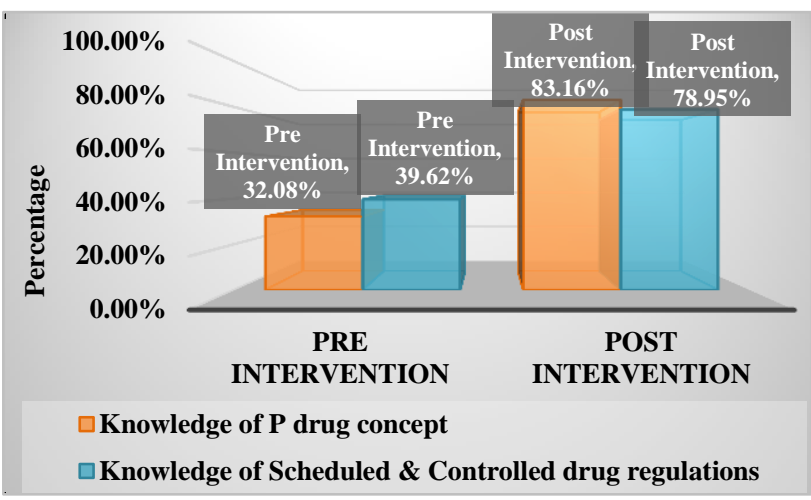

Figure 4: Knowledge of $P$ drug concept scheduled \& controlled drug regulations.

Table 5: Scoring for Computerized transmission of prescriptions (Statistical analysis done by chi-square test).

\begin{tabular}{llll}
$\begin{array}{l}\text { Computerized } \\
\text { transmission of } \\
\text { prescriptions with } \\
\text { standard format } \\
\text { will help avoid } \\
\text { possible errors }\end{array}$ & $\begin{array}{l}\text { Pre } \\
\text { intervention }\end{array}$ & $\begin{array}{l}\text { Post } \\
\text { intervention }\end{array}$ & $\begin{array}{l}\text { P } \\
\text { Value }\end{array}$ \\
\hline Yes & $47.60 \%$ & $68.40 \%$ & $<0.001$ \\
\hline No & $52.40 \%$ & $31.60 \%$ & \\
\hline
\end{tabular}

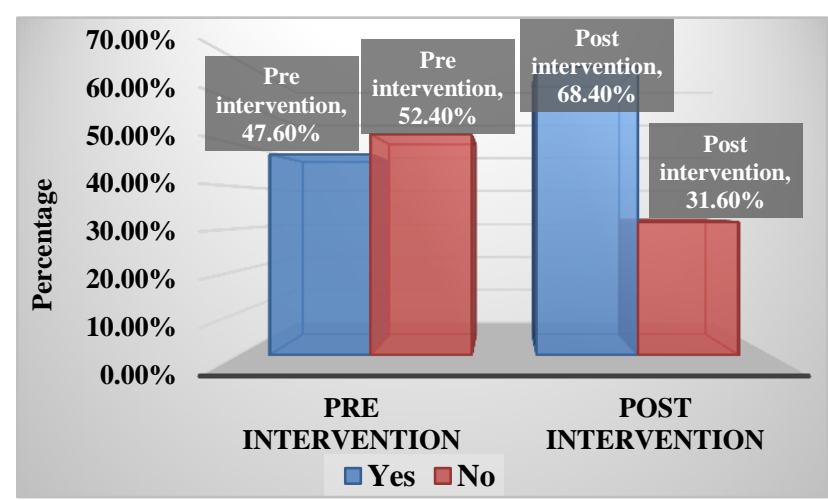

Figure 5: Computerised transmission of prescriptions with standard format will help avoid possible errors.

Most of the Interns (95\%, both pre and post intervention) think that their prescription skill can be improved by training/ refreshing course before starting their internship. Hence, we need to conduct such training courses for the interns to improve their prescription skills and knowledge about clinical pharmacology and thus pave way for rational prescribing among the future Physicians.

We divided the total number of interns after the educational intervention into nine groups and gave nine different clinical scenarios and they were asked to write a prescription for the same. Later the prescriptions were scrutinized and mistakes were pointed out and the precise way of writing the same was explained to the interns. The summary of the analysis of the Prescriptions are as follows.

Table 6: Deficiencies in inscription part of the prescriptions analysed.

\begin{tabular}{|llll|}
\hline S. No & Deficiencies & Yes & No \\
\hline 1 & Diagnosis & 9 & 0 \\
\hline 2 & Rx symbol & 8 & 1 \\
\hline 3 & Drug name & 9 & 0 \\
\hline 4 & Drug Formulation & 9 & 0 \\
\hline 5 & Route of administration & 3 & 6 \\
\hline 6 & Instruction & 6 & 3 \\
\hline 7 & Frequency & 9 & 9 \\
\hline 8 & Duration of Treatment & 9 & 0 \\
\hline
\end{tabular}

In the superscription only six out of nine prescriptions were complete (Figure 6). There were lacunae in the doctors details in 1 , patient details in 2 , absent date or contact details in 2 prescriptions (Figure 7). And contact details were not mentioned in 3 prescriptions.

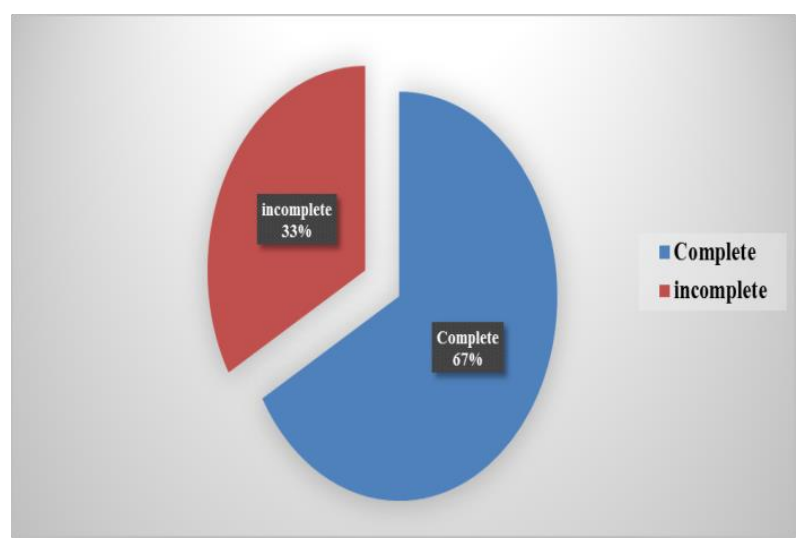

Figure 6: Completeness of superscription.

In the Inscription section of the prescription, also there were certain deficiencies which is shown in table 6 and depicted in Figure 8. There were $78 \%$ of prescriptions with correct dosage of the drugs (Figure 9A) and $89 \%$ of 
them have used only generic name of the drugs while prescribing (Figure 9B).

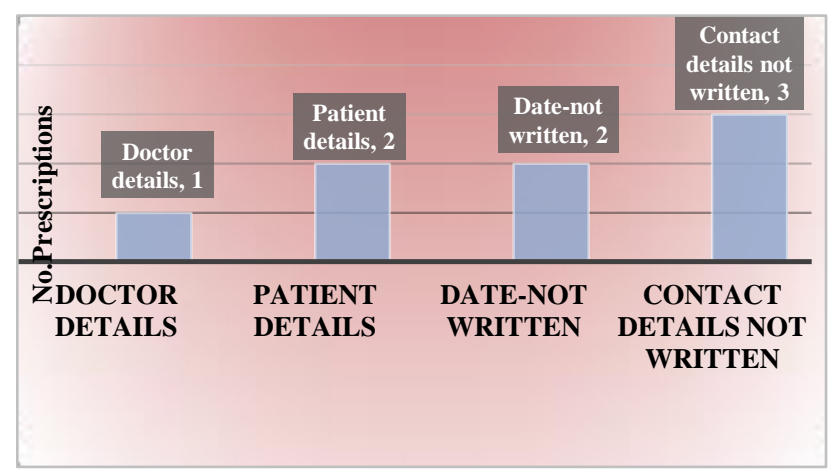

Figure 7: Deficiencies in superscription.

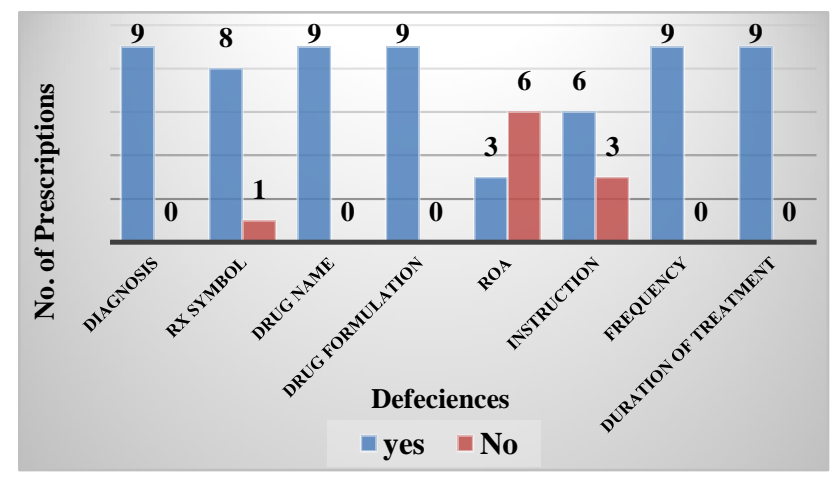

Figure 8: Defeciences-inscription.

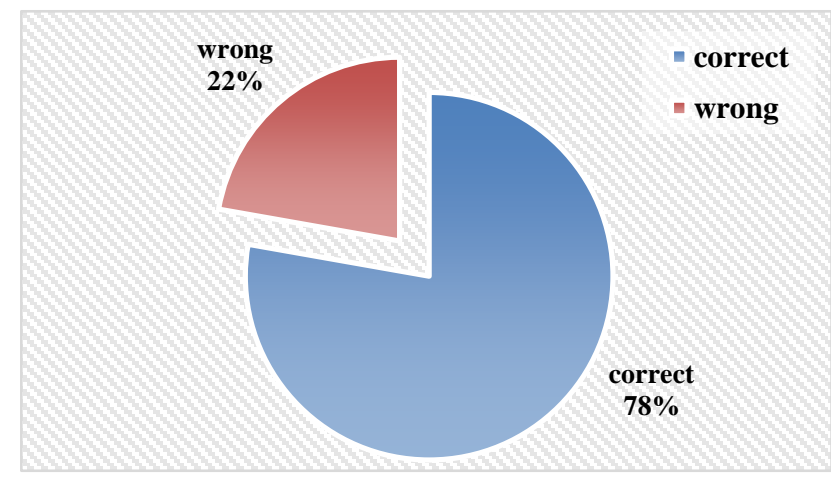

Figure 9A: Drug dose.

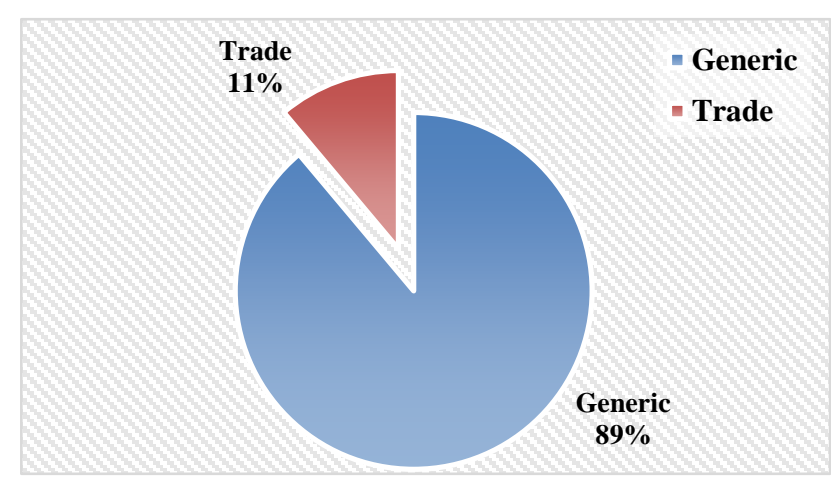

Figure 9B: Drug name usage.
On analysis of the subscription part of the prescriptions it was found out that only one prescription was lacking both the prescriber's signature $(11 \%)$ and instruction to the patient. Other prescriptions (89\%) had completed subscription without any lacunae (Figure 10).

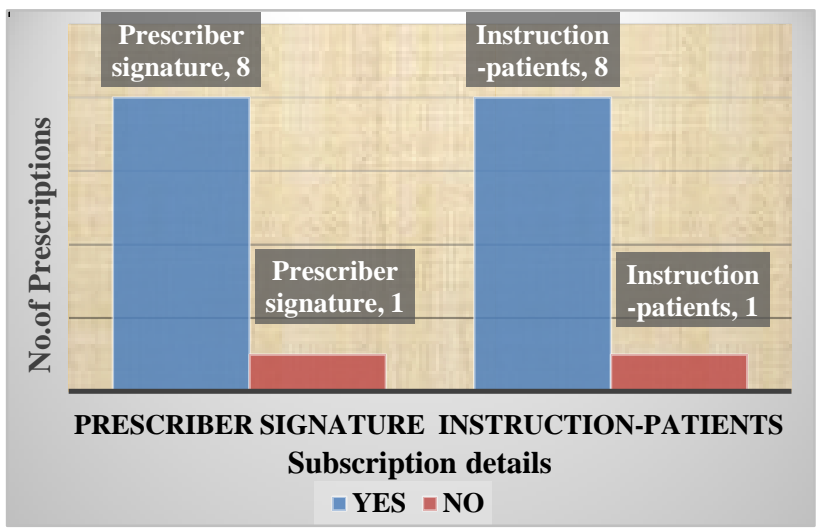

Figure 10: Subscription details.

\section{DISCUSSION}

In this study the knowledge of interns' regarding Prescription writing has presented a marked increase after subjecting them to an educational intervention which goes in hand with the study results of the systematic review done by Kamrudeen, et al. ${ }^{6}$ This study stands unique in its way, as we have assessed the knowledge and attitude of the Interns' on prescribing, both before and after the educational intervention and also gave hands on training on rational prescribing and audited the same.

Our study results reveal that $78.9 \%$ of Interns opted to prescribe drugs in Generic name after recognizing the advantages of Generic name. There is a significant improvement in the knowledge about the benefits of prescribing in generic name as it will be cost effective and it will remove the problem in remembering and recalling the trade name as expressed by some interns in studies. On further analysis of the questionnaire, it was found out that there is an increase in the percentage of interns from $29 \%$ to $40 \%$ who prefer to follow standard guidelines while deciding the treatment plan after the educational intervention. There is a significant improvement in the knowledge about the different components and their required contents of the prescription after the intervention. Significant improvement in the knowledge about the $\mathrm{P}$ drug concept and scheduled \& controlled drug regulations was also observed after the educational intervention. There is also a significant increase in the percentage of interns from $47.6 \%$ to $68.4 \%$ after the educational intervention who opted for computerized transmission of prescriptions with standard prescription format to avoid possible manual errors like illegible handwriting, errors in writing correct decimals and strength ( $\mathrm{mg}, \mathrm{ml}$ etc) But, before the educational intervention the knowledge of Interns on 
clinical Pharmacology seems to be lacking in certain fields as stated above.

On analysis of the Prescriptions it was found out that in the superscription, only six out of nine prescriptions were complete (Figure 6). There were lacunae in the doctors details, patient details, date or contact details which are essential for further follow up. In the Inscription section of the prescription, also there were certain deficiencies in route of administration, frequency and advice to the patients, which is shown in Table 6 and depicted in figure 8. Unless they are written correctly chances for therapeutic failure or toxicity are there. Even though there were $78 \%$ of prescriptions with correct dosage of the drugs (Figure 9) and $89 \%$ of them have used only generic name of the drugs (Figure 10) they can be improved to the target of achieving $100 \%$ as per WHO guidelines by such periodic awareness programs. On analysis of the subscription part of the prescriptions it was found out that only one prescription (11\%) was lacking both the prescriber's signature $(11 \%)$ and instruction to the patient. In a study done to assess the knowledge and attitudes of interns to medication prescribing errors in a Nigerian tertiary hospital it was found out that some essential information such as duration of therapy, patient age and dosage errors were the most common types of prescribing errors made. $^{7}$

All the prescriptions were rational except for one in which superfluous usage of Proton pump inhibitors was encountered which can be avoided. The same was then conversed to the Interns and advised not to overprescribe medicines.

In a study done to assess the prescribing knowledge, attitude \& practice of interns and post-graduates of a tertiary care hospital in India it was found out that $50 \%$ of the interns and postgraduates felt that they do not have good knowledge in prescribing medicines. Majority have stated that the medical curriculum needs to be amended to incorporate this training. ${ }^{8}$ As Pharmacology stands as the backbone of clinical discipline of medical science; amendment has to be made in this field to give special training courses for Interns to improve their prescription skills.

Study done by Zakirul Islam, et al on interns shows that the pharmacology and therapeutics course curriculum during the undergraduate period is not enough to produce safe prescribers. ' A pilot study done among interns' in Nigeria also suggests that undergraduate teaching in Nigeria appears to be deficient and Medical students and interns should be assessed periodically on prescribing knowledge and skills during their training which will lead on to minimizing prescribing errors ${ }^{10}$.Study done by Patiet, al stress that the promotion of optimal drug prescribing and safe drug use should be emphasized during the internship period. ${ }^{11}$
A study done by Shailesh Mundhav, et al on the knowledge, attitude and practise of prescribing in interns and post graduates reveals that they do not have good knowledge in prescribing medicines and majority felt that the curriculum needs to be modified to encompass this training. ${ }^{12}$ Another study done at a primary health centre in India also reveals similar fact that irrational prescribing practices are common among interns and hence the art of rational prescribing should be imparted to them by medical teachers to avoid irrational prescribing, as felt by us. $^{13}$

In this study also most of the Interns (95\%, both pre and post intervention) think that their prescription skill can be improved by training/refreshing course before starting their internship. Hence, we need to conduct such training courses for the interns on rational prescribing to improve their prescription skills and knowledge about clinical pharmacology and thus pave way for rational prescribing among the future Physicians.

\section{Strengths and limitations of the study}

This study had a major advantage of combining two forms of educational interventions, a theoretical intervention in the form of a lecture on rational prescribing and another practical hands-on training on Prescription writing and auditing of the same. This unique aspect of this study makes it to stand apart from rest of the studies.

The only limitation to this study was the number of participants and focused group of participants. The results may not be generalized and extrapolated to all MBBS interns. This type of training courses for the interns on rational prescribing should be made mandatory before they step into their internship program to avoid prescription errors and lead on to a better rational prescribing practice among the future Physicians.

\section{CONCLUSION}

The definitive positive impact of CME and Practical hands on training on rational prescribing has been evidenced in our study. Our study clearly shows that the educational intervention has improved the knowledge and attitude of interns towards clinical pharmacology, which was reflected in their feedback and prescriptions which were rational. Inclusion of such educational intervention/training programs in the MCI curriculum for the interns can be suggested.

\section{ACKNOWLEDGEMENT}

We would like to place our acknowledgement to the faculties of Department of Pharmacology, and most importantly to the MBBS interns and the management of Sri Venkateshwaraa Medical College Hospital and Research Centre, Pondicherry for their voluntary participation and co-operation. 
Funding: No funding sources

Conflict of interest: None declared

Ethical approval: The study was approved by the Institutional Ethics Committee

\section{REFERENCES}

1. Chaurasia RC. Pharmacology exercise for undergraduate: MLNMC model. Int J Basic Clin Pharmacol. 2013;2(4):495-7.

2. Mohan L, Chogtu B, Adiga S, Shenoy S, Bairy KL, Kishore A. Undergraduate medical students' perceptions regarding personal drug selection exercise. International Journal of Pharmacology and Clinical Sciences. 2012;1(2):61-7.

3. Upadhyaya P, Seth V, Sharma M, Ahmed M, Moghe VV, Khan ZY, et al. Prescribing knowledge in the light of undergraduate clinical pharmacology and therapeutics teaching in India: views of firstyear post graduate students. Adv Med Educ Pract. 2012;3:47-53.

4. Velo GP, Minuz P. Medication errors: prescribing faults and prescription errors. Br J Clin Pharmacol, 2009;67(6):624-8.

5. Pote S, Tiwari P, D'Cruz S. Medication prescribing errors in a public teaching hospital in India: A prospective study. Pharm Pract (Granada). 2007;5(1):17-20.

6. Kamarudin G, Penm J, Chaar B. Educational interventions to improve prescribing competency: a systematic review. BMJ Open. 2013;3:e003291.
7. Ajemigbitse AA. Assessment of the knowledge and attitudes of intern doctors to medication prescribing errors in a Nigeria tertiary hospital. Journal of Basic and Clinical Pharmacy. 2014;5(1).

8. Mundhava S, Lalwani U, Pillai A. Prescribing knowledge, attitude, practice of interns and postgraduates of a tertiary care hospital in India. World journal of pharmacy and pharmaceutical sciences. 2000;4(6):451-8.

9. Islam Z. Assessment of Bangladeshi Interns' Knowledge of Pharmacology and Therapeutics for Prescribing. Journal of Applied Pharmaceutical Science. 2014;4(4):43-51.

10. Oshikoya KA. Interns' knowledge of clinical pharmacology and therapeutics after undergraduate and on-going internship training in Nigeria: a pilot study. BMC Medical Education. 2009;9:50.

11. Pati RR. Prescribing patterns among medical interns at the rural health centers of a medical college, Manipal, Karnataka. Indian Journal of Community Medicine. 2004;29(3).

12. Mundhava S. Prescribing knowledge, attitude, practice of interns and post-graduates of a tertiary care hospital in India. World Journal Of Pharmacy And Pharmaceutical Sciences. 1998;4(6)451-8.

13. Banerjee I, Bhadury T. Prescribing pattern of interns in a primary health centerin India. Journal of Basic and Clinical Pharmacy. 2014;5(2).

Cite this article as: Saravanan R, Sakthibalan M, Meher BR, Balabalajee J. Effect of educational intervention on the knowledge and attitude on prescribing amongst interns of a tertiary care hospital: a questionnaire based study. Int $\mathrm{J}$ Basic Clin Pharmacol 2016;5:366-73. 